\title{
From experiment to publication in one semester: a lecture course model on the basis of a photonic researcher's every-day tasks
}

Christoph Gerhard, Stephan Wieneke

Christoph Gerhard, Stephan Wieneke, "From experiment to publication in one semester: a lecture course model on the basis of a photonic researcher's every-day tasks," Proc. SPIE 9793, Education and Training in Optics and

Photonics: ETOP 2015, 97932R (8 October 2015); doi: 10.1117/12.2223235

SPIE Event: Education and Training in Optics and Photonics: ETOP 2015, 2015, Bordeaux, France 


\title{
From experiment to publication in one semester: A lecture course model on the basis of a photonic researcher's every-day tasks
}

\author{
Christoph Gerhard*, Stephan Wieneke \\ HAWK - University of Applied Sciences and Arts, Faculty of Natural Sciences and Technology, \\ Von-Ossietzky-Straße 99, 37085 Göttingen, Germany
}

\begin{abstract}
We report on a lecture course model that we established three semesters ago in order to strengthen practice-orientated teaching in optics and photonics: In the frame of the lecture "Advanced Laser Treatment", which is a mandatory course of our university's master degree curriculum, students now have the possibility to experience a researcher's every-day tasks. In small groups, the attendees work on a self-contained topic which is defined by the lecturers. The work load and content is in the scale of a small work package of a usual research project. It includes the initial research on the state of the art, the experimentation using different laser sources, and the subsequent evaluation of the obtained results. On the basis of this work, the students then prepare a draft of a scientific paper and finally present their results and findings orally in a conference-like exam.

This lecture course model has turned out to be an appropriate teaching method for practice-orientated subjects. It was observed that the students are much more motivated and work more independently than during a classical lecture with a certain amount of lab work. Having sole responsibility supports to identify with their project. Further, this lecture course model helps to develop scientific work skills, attain first experience in every-day research tasks and encourages creativity. In some cases, the paper drafts written by the students can even be published, representing a valuable starting point for their future professional career.
\end{abstract}

Keywords: lecture course model, practice-orientated teaching, developing scientific skills, motivation, individual responsibility

\section{INTRODUCTION}

As a result of the Bologna process, the formerly existing concept of a 4-years diploma degree programme at German polytechnics (universities of applied sciences) was replaced by either 3-years bachelor programmes or 5-years master programmes in the last few years. The mandatory practical semester, which was an essential part of the curricula of practice-oriented diploma studies until then, was cancelled in the course of this change. In order to ensure an appropriate practical content, several practical laboratory courses were added to the master degree curricula at the Faculty of Natural Sciences and Technology of the University of Applied Sciences and Arts (HAWK) in Göttingen, Germany. Against this background, the lecture "Advanced Laser Treatment", involving a very high percentage of practical content, has become a mandatory course for the study programmes "Optical Engineering/Photonics" (Master of Science, M.Sc.) and "Precision Mechanical Engineering" (Master of Engineering, M.Eng.). In addition, this lecture is offered bachelor students of the study programme "Physical Technologies" (Bachelor of Engineering, B.Eng.) as a compulsory optional subject. The concept and course model which was established three semesters ago is presented and discussed in this contribution.

\section{THE LECTURE COURSE MODEL}

According to the title of this contribution, the idea of our lecture course model was to allow the students to get in touch with a researcher's scientific every-day tasks and to provide an insight into the methods of scientific test planning, experimentation, and publishing. For this purpose, self-contained projects with a work load and content in the scale of a small work package of a usual research project are defined by the lecturers. These projects are then treated by the course

*christoph.gerhard@hawk-hhg.de; phone +49 5513705 376; hawk-hhg.de

Education and Training in Optics and Photonics: ETOP 2015, edited by Eric Cormier, Laurent Sarger Proc. of SPIE Vol. 9793, 97932R · C 2015 SPIE, IEEE, OSA, ICO · doi: 10.1117/12.2223235 
attendees in group work. This includes the initial research on the state of the art, the experimentation using different laser sources, optical setups and auxiliary tools, and the subsequent evaluation of the obtained results using appropriate measurement equipment. On the basis of their results and findings, the students then prepare a draft of a scientific paper and finally present their work orally in a conference-like exam. The presented lecture course model can thus be referred to as a problem-based learning (PBL) method where the given task of the project represents the problem which encourages the cognitive process as introduced by Barrows [1,2]. According to the module description, the lecture "Advanced Laser Treatment" comprises 60 contact hours and 120 hours for self-studies are required additionally. Nominally, the scheduled expenditure of time thus sums up to 180 hours in total, which is a sufficient space of time for processing the given work load. The balance of both the designed problem and the space of time available for solving it is an important aspect for a successful implementation of PBL methods [3].

In this course model, the lecturers have several functions: In the frame of the introductory lecture, basics of laser material processing and associated topics are communicated. Further, an introduction to how to write a scientific paper and how to prepare a scientific talk including essential contents, styles and dos and don'ts is given. Terminally, the particular projects are presented and the attendees are divided into groups of 2-4 students per project. At the beginning of the experimental phase, a short course on laser safety as well as a brief introduction to the experimental setup is given. Further, use of the required measurement equipment for evaluation such as microscopes, profile meters etc. is taught. The students then work independently on the given project in order to develop problem solving skills by PBL [4]. In case of any arising problems or questions they are collaterally coached and assisted by the lecturers and/or laboratory engineers who thus act as tutors [5]. Finally, the papers written by the students (i.e. normally 10 papers, 1 per group) are read and rated. The exam, which consists of a 15-minutes talk in a conference-like situation, is followed by a maximum 15-minutes question time where the lecturers test each candidate individually regarding the results, findings and conclusions of the particular project. As shown by Krajeik and co-workers, this type of exam is generally more beneficial and sustainable than a classical written test [6].

The student's activities are highly practice-orientated. According to the underlying concept of this course model on the basis of a photonic researcher's every-day tasks, these activities involve classical literature research, the realisation, modification and adjustment of experimental setups, both the experimentation and evaluation, and the presentation of results and findings in written and oral form. Generally, each student's activity is closely connected with particular educational objectives as listed in more detail in figure 1.

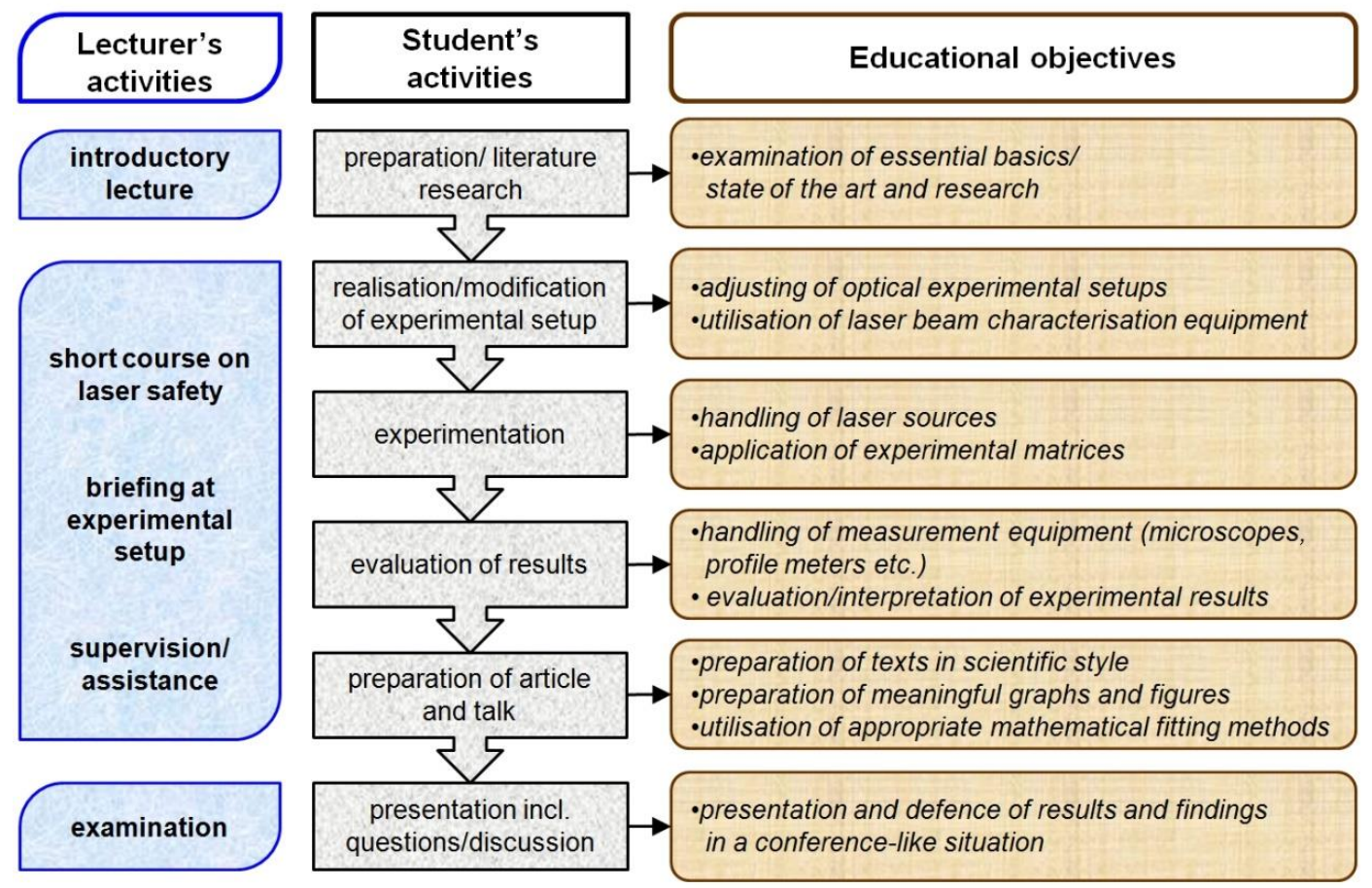

Figure 1. Schematic of the presented lecture course model 


\section{MATERIALS AND METHODS FOR PRACTICAL TEACHING}

For working on the given projects, UV, VIS, NIR, and IR laser sources which are available at the HAWK are used by the students, i.e.:

- several short pulse solid-state laser sources with discrete wavelengths from 266 to $1,064 \mathrm{~nm}$,

- several nanosecond dye lasers with discrete wavelengths in the range from 200 to 2,000 nm,

- a xenon chloride excimer laser with an emission wavelength of $308 \mathrm{~nm}$,

- a carbon dioxide laser with a wavelength of $10.6 \mu \mathrm{m}$, and

- a continuous-wave diode laser with a wavelength of $808 \mathrm{~nm}$.

In some cases, these are commercial laser work stations with xyz-positioning systems or galvano scanner units. However, the main part of these laser sources provides laser raw beams and is arranged on optical tables where experimental opto-mechanical test rigs, e.g. beam homogenisers or beam expanders, are additionally set up. Here, the students learn the basics of laser beam shaping and guiding and how to align optical setups. For the alignment and process control, appropriate laser beam characterisation equipment such as

- power and energy meters,

- cameras for beam profile analysis,

- a Shack-Hartmann wavefront sensor, and

- a rotating hollow needle laser beam diagnostic system

is used. In the course of the project, the students further learn the handling of laser sources, galvano scanner units and motorised xyz-positioning systems during experimentation, assisted and advised by a lecturer and/or laboratory engineer if desired. The subsequent evaluation and interpretation of the experimental results is carried out with the aid of suitable measurement equipment, for example

- several light microscopes,

- a scanning electron microscope (SEM),

- an atomic force microscope (AFM),

- a tactile profile meter,

- a tensile tester as well as

- an adhesive pull strength tester.

The choice of the right measurement equipment is incumbent on the students and depends on the project specifications, i.e. the measured values of interest (e.g. ablation spot diameter and depth, surface roughness, weld seam stability etc.). Once these data are collected the students work on the preparation of meaningful graphs and figures for the paper draft and the presentation. For this purpose, the interrelationships of the measured data and the applied laser parameters are analysed using appropriate evaluation software such as OriginLab for applying mathematical fitting methods. The use of all the above-mentioned materials and methods is intended to support the educational objectives as listed in more detail in figure 1 .

\section{SELECTED PROJECTS}

The presented course model was first implemented in winter semester 2012/2013. Since that time, approximately 90 attendees and 30 groups, respectively, have worked on different projects. The topics of these projects cover a wide range of laser applications for surface treatment: classical ablation such as drilling, marking and cutting, but also laser welding and laser surface modification such as polishing or annealing. In some cases, hybrid laser-based methods including auxiliary tools such as atmospheric pressure plasma sources or hot air guns are applied. A selection of some past projects including the main findings and the used equipment is given below.

\section{Laser cutting of wooden veneers}

In this project, laser beam cutting of wooden veneers was investigated using a Nd:YAG-laser at its fundamental wavelength of 1,064 $\mathrm{nm}$. The cut edges were evaluated by light microscopy. The results show the suitability of the used laser for cutting veneers. However, the scan speed of the laser focus was identified as the main influencing parameter. In order to avoid thermal damage of the peripheral zones by pyrolysis, the process window was determined. 


\section{Laser ablation of heavy flint glasses at $1,064 \mathrm{~nm}$}

Optical heavy flint glass was ablated by Nd:YAG-laser irradiation at a wavelength of 1,064 $\mathrm{nm}$. In addition, an atmospheric pressure plasma jet and a hot air gun were introduced to the process. The glass surfaces were evaluated by light microscopy after experimentation. It was shown that the use of a hot air gun notably influences the ablation process by pre-heating the glass surface.

\section{Laser and laser-plasma-hybrid micro polishing of nickel plated stainless steel surfaces}

Polishing of nickel surfaces was performed using a Nd:YAG-laser at the fundamental wavelength of 1,064 nm with and without an assisting low-temperature atmospheric pressure argon plasma. The nickel surfaces were measured by atomic force microscopy. A maximum decrease of the roughness peak height by a factor of 2.9 was achieved.

\section{Laser welding of steel with a Nd:YAG laser}

The aim of this project was to investigate laser welding of stainless steel devices using a low-power Nd:YAG-laser at a wavelength of 1,064 $\mathrm{nm}$. The stability of the produced welding seams was investigated by a tensile tester. Further, the welding seams were evaluated visually by light microscopy. Even though a relatively low laser power was applied, dense and crack-free welding seams could be realised by varying the laser focus scan speed.

\section{Ablation of polyoxymethylene by excimer laser irradiation at $308 \mathrm{~nm}$}

The ablation characteristics of polyoxymethylene (POM) were investigated using a xenon-chloride excimer laser at a wavelength of $308 \mathrm{~nm}$. By the evaluation of the generated ablation spots using light microscopy, the ablation threshold was experimentally determined to amount to $7.1 \mathrm{~J} / \mathrm{cm}^{2}$. When increasing the laser fluence, an increase in the ablation spot diameter was observed whereas the form error reached a saturation value very soon.

\section{Atmospheric pressure plasma-assisted laser annealing of amorphous silicon layers}

In this project, plasma-assisted NIR-laser annealing of amorphous silicon coatings was investigated and compared to UV-laser annealing. The laser-irradiated coating surfaces were evaluated by light microscopy. It was observed that in principle, NIR lasers are suitable for the crystallisation of amorphous silicon.

\section{Comparison of ablation characteristics of silicon carbide using UV and NIR lasers}

Silicon carbide samples were drilled using different laser sources wit wavelengths in the UV and NIR range. The experiments were carried out with and without the use of an auxiliary plasma source. The drilled holes were then evaluated by light microscopy and tactile profilometry. It was found that the used UV-laser is more suitable for machining the given material and that the assisting plasma allows a reduction of laser-induced debris.

\section{SUCCESSES AND FUTURE TRENDS}

According to the feedback from the attendees, the presented lecture course model is an appropriate teaching method for practice-orientated subjects. In comparison to a classical lecture with a certain amount of lab work, the students are much more motivated and work more independently due to the fact that they take on sole responsibility for their project. Such responsibility significantly supports the students to identify with the project and to develop creativity and scientific work skills by getting in touch with every-day research tasks. Some particular individual successes are highlighted below:

In one case, a student prepared his master thesis on the basis of the project he worked on during the lecture "Advanced Laser Treatment". For this purpose, further series of experiments were defined and performed based on the results which were obtained during the practical project. This student passed the final examination and now works in industry. Since the results of his master thesis were of extraordinary quality, he and the lecturers prepare a patent application and a journal article presently. Further, two paper drafts which were written in the frame of other projects are currently revised by the students and the lecturers. In case of acceptance and publication, this represents a valuable starting point for the future professional career of the respective students. In the course of the evaluation of their results, another group of students wrote a software program which automatically detects the contour of laser-ablated spots in order to determine the effective ablated area and contour accuracy on the basis of microscopy images. Currently, this program is refined by the students and will be beta tested very soon by scientists of the HAWK's Laboratory for Laser and Plasma 
Technologies. In the case of a provable reliability, the introduction of the program will be a part of a planned research paper dealing with the comparison of laser ablated spots with and without the use of an auxiliary plasma source.

In consequence of these successes, the presented course model could also be applied to other mandatory lectures at our university, for example "Laser Material Processing", "Laser as Production and Diagnostic Tool", and "Applied Laser Measurement". We are confident that our approach, "from experiment to publication in one semester", could also be of interest for other lecturers and professors who teach practice-orientated subjects and who are interested in alternative methods of instruction.

\section{ACKNOWLEDGEMENTS}

The support by the Volkswagen Foundation and the Federal State Lower Saxony by the sponsorship of the research professorship for Laser-Plasma-Hybrid Technology at the University of Applied Sciences and Arts in the frame of the state funding program "Niedersächsisches Vorab" is gratefully acknowledged.

\section{REFERENCES}

[1] Barrows, H.S., "Problem-based learning in medicine and beyond: A brief overview", New Directions for Teaching and Learning 1996(68): 3-12 (1996).

[2] Neville, A.J., "Problem-based learning and medical education forty years on. A review of its effects on knowledge and clinical performance", Medical Principles and Practice, 18(1): 1-9 (2009).

[3] Hung, W., "Theory to reality: A few issues in implementing problem-based learning", Educational Technology Research and Development, 59(4): 529-552 (2011).

[4] Hmelo-Silver, C.E., "Problem-based learning: What and how do students learn?", Educational Psychology Review, 16(3): 235-266 (2004).

[5] Schmidt, H.G., Rotgans, J.I., Yew, E.H.J., "The process of problem-based learning: What works and why", Medical Education, 45(8): 792-806 (2011).

[6] Krajeik, J., Blummenfeld, P.C., Marx, R.W., Soloway, E., "Collaborative model for helping middle grade science teachers learn project-based instruction", Chicago Journals, 94(5): 483-497 (1994). 